have hitherto limited the precision of measurements by the mixtures method. The method consists in making strictly comparable measurements with a substance of known heat capacity. The containers for the two substances are made identical, and the quantity of the reference substance used is so adjusted that the same temperature change is obtained in the calorimeter as with the substance under examination. Water has been used as the reference substance in this investigation, and the values of its heat capacity as determined by Bousfield have been employed in the calculations.

An automatic device has been described, whereby the substance whose heat capacity is to be determined may be lowered rapidly from the thermostat into the calorimeter under strictly reproducible conditions.

The mean specific heat capacity of liquid ammonia has been measured for the temperature intervals $0^{\circ}-20^{\circ}$, and $20^{\circ}-50^{\circ}$. Its value expressed in $15^{\circ}$ calories is $1.15^{2}$ between $0^{\circ}-20^{\circ}$ and $1.17^{2}$ between $20^{\circ}-50^{\circ}$. The equation for the true specific heat capacity obtained from these data (assuming it to be linear function of the temperature) is

Cambridge, Mass.

$$
\mathrm{C}_{s}=\mathrm{I} . \mathrm{I} 44+0.0008 t
$$

[Contribution from the Research Laboratory of Phystcal Chemistry of the MASSACHUSETTS INSTITUTE OF TEChNOLOGX, No. I08.]

\title{
THE RELATIVE ELECTRODE POTENTIALS OF TIN AND LEAD DETERMINED BY EQUILIBRIUM MEASUREMENTS WITH THEIR PERCHLORATES.
}

By ARThur A. NOYes AND KEBE TOABE.

Received May 26, 1917.

Contents.-1. Purpose of the Investigation. 2. Review of Previous Equilibrium Studies. 3. Preparation of the Substances and Solutions. 4. Methods of Analysis. 5. Method of Preparing the Equilibrium Mixture. 6. The Results of the Equilibrium Measurements. 7. Value of the Equilibrium Ratio. 8. Comparison of the Equilibrium Ratios Obtained with the Perchlorates and the Chlorides. 9. Difference between the Specific Electrode Potentials of Tin and Lead. Io. The Specific Electrode Potentials of Lead and Tin. II. Summary.

\section{Purpose of the Investigation.}

The specific electrode potential of tin is shown by previous determinations to be not far different from that of lead, but its value is not accurately established. A satisfactory method of determining the difference between this electrode potential and that of lead would seem to be to allow one of these metals to come to equilibrium with an aqueous solution of some salt of the other metal. As the electrode potentials are nearly equal, both metallic elements would be found in solution at the end in amounts large enough to determine by chemical methods. The study of this 
equilibrium with salts of known ionization relations would lead directly to a precise calculation of the difference between the specific electrode potential of tin and that of lead. The latter potential can be computed from existing data with a fair degree of accuracy, as shown in a later section of this article. This investigation was therefore undertaken to determine directly the equilibrium constant of the reaction

$$
\mathrm{Sn} \text { (solid) }+\mathrm{Pb}^{++}\left(\mathrm{ClO}_{4}^{-}\right)_{2}=\mathrm{Pb} \text { (solid) }+\mathrm{Sn}^{++}\left(\mathrm{ClO}_{4}^{-}\right)_{2} \text {. }
$$

The perchlorates were used, as these salts are free from objections which apply to many of the other salts of lead or tin.

For preliminary experiments bearing upon this investigation and for a study of the methods of analysis involved, we are indebted to Messrs. R. V. Townend and E. J. Casselman. We wish also to express our thanks to Dr. M. S. Sherrill for valuable suggestions throughout the course of the research, and to Mr. R. G. Dickinson for assistance in preparing the article for publication.

\section{Review of Previous Equilibrium Studies.}

O. Sackur ${ }^{1}$ studied the equilibrium of reactions between lead and tin and their salts, using the acetate, nitrate, sulfate, and chloride. The acetate solutions hydrolyzed considerably. In the nitrate solutions the excess of nitric acid used to prevent hydrolysis was partially reduced to hydroxylamine by the metallic tin. In the case of the sulfates, the insolubility of lead sulfate resulted in very low metal-ion concentrations and consequent analytical difficulties. The chlorides gave measurements that were satisfactory, but difficult of interpretation because of the possibility of abnormal ionization and the formation of complex anions. Sackur's results with chlorides will be considered in detail later.

The perchlorates should be free from these various objections. Perchloric acid is one of the strongest acids, and it is not reduced in aqueous solution even by zinc or aluminum. The lead and tin perchlorates are soluble, and probably show normal ionization, like the nitrates.

\section{Preparation of the Substances and Solutions.}

Finely powdered metallurgical silver-free lead was found by three closely agreeing analyses (precipitation as sulfate) to contain $99.70 \% \mathrm{~Pb}$, the remaining $0.30 \%$ probably being oxygen arising from the presence of oxide. The lead was melted in an iron ladle, using lard oil to preven further oxidation; and it was then poured into a graphite mold. The ingot obtained was turned into fine shavings on a lathe. Both turnings and powdered lead were used in the equilibrium experiments.

The tin was a sample from Merck shown by analysis to be free from lead, copper, iron and zinc. The tin was cast into ingots and turned in a lathe to very fine shavings.

\footnotetext{
${ }^{1}$ Arb. kais. Gesundh., 20, 512 (1903); also Z. Elektrochem., 10, 522 (1904).
} 
The perchloric acid was made by the distillation of potassium perchlorate with concentrated sulfuric acid under reduced pressure. The perchloric acid was redistilled until it gave no test for sulfuric acid with barium chloride.

A lead perchlorate solution (0.1003 formal) was prepared by dissolving pure lead carbonate in an excess of perchloric acid.

Stannous perchlorate solution was prepared indirectly. Pure cupric oxide was dissolved by boiling it with an excess of dilute perchloric acid. To this copper perchlorate solution, after cooling, tin shavings in large excess were added. The copper separated out completely as a spongy deposit, leaving a clear colorless solution of stannous perchlorate. The solution was filtered through asbestos in an atmosphere of carbon dioxide and in contact with metallic tin, and it was kept in glass-stoppered bottles filled with carbon dioxide, and containing metallic tin. On standing a few days the solution developed a yellow coloration, but remained perfectly clear. In order to test whether hydrolysis or other change was taking place to an appreciable extent, a fresh perchlorate solution was placed in a conductivity cell which had been previously evacuated, and its conductance was measured each day for twelve successive days. The conductance remained constant, showing that the ion concentrations did not change during the development of the yellow color.

\section{Methods of Analysis.}

After long preliminary investigations of methods for determining lead in the presence of tin, certain difficulties encountered were overcome and the following procedure was adopted: A weighed quantity of the equilibrium mixture containing from $0.25-0.50 \mathrm{~g}$. $\mathrm{Pb}$ was diluted to about $150 \mathrm{cc}$, and $30 \mathrm{cc}$. of nitric acid (sp. gr. I.43) were added. The solution was electrolyzed with a current of 0.5 ampere for $2 \frac{1}{2}$ to 3 hours between a sand-blasted cylindrical platinum-gauze anode with an area of $80 \mathrm{sq} . \mathrm{cm}$. and a platinum-foil cathode $\mathrm{I} \mathrm{sq.} \mathrm{cm}$. in area rotated at about IOO revolutions per minute. At the end of the electrolysis the liquid was syphoned off, wash water (about two liters) being gradually added at the same time till all acid was removed. The current was then broken, and the gauze was placed in a mixture of 15 cc. nitric acid (sp. gr. I.43), $150 \mathrm{cc}$. water, and $2 \mathrm{cc}$. of $3 \% \mathrm{H}_{2} \mathrm{O}_{2}$ solution. The lead dioxide immediately dissolved. The solution was then evaporated on a water bath, the residue was dissolved in $25 \mathrm{cc}$. of very dilute nitric acid, and the solution was filtered through hardened filter paper, diluted to about I5O cc., treated with $30 \mathrm{cc} . \mathrm{HNO}_{3}$ (sp. gr. I.43) and electrolyzed as before. The anode was washed, dried at $200-220^{\circ}$ in an electric oven for 2 hours, and then weighed. ${ }^{1}$

1 It is impossible to remove the last traces of water from the precipitated $\mathrm{PbO}_{2}$ even by prolonged heating at $200-220^{\circ}$; hence, the weight of the precipitate is always 
Two electrolyses were found necessary because of the occlusion of several per cent. of stannic oxide in the first precipitate. That this was completely removed by the subsequent treatment was shown by test analyses made by dissolving about $0.5 \mathrm{~g}$, of pure metallurgical lead in nitric acid, diluting, adding about the amounts of stannous perchlorate and perchloric acid present in the equilibrium mixtures, and electrolyzing under the conditions described above. Three such analyses gave $99.63,99.56$ and $99.55 \% \mathrm{~Pb}$, instead of the $99.70 \%$ found by precipitation as sulfate.

The amount of tin in the equilibrium mixtures was determined by titration against $0.1 N$ permanganate. The solution to be analyzed was drawn up into a pipet filled with carbon dioxide, 25 to 50 cc. were delivered into a weighed glass-stoppered flask also filled with carbon dioxide, and weighed. Then $25 \mathrm{cc}$. of $20 \% \mathrm{HClO}_{4}$ were added, and the solution was titrated, $35-50 \mathrm{cc}$. of the permanganate being used. Sulfuric acid could not be used instead of perchloric acid because the precipitated lead sulfate occluded tin and caused low results.

For the determination of the free perchloric acid a weighed portion of the equilibrium mixture was diluted and saturated with hydrogen sulfide. After the sulfides had settled, they were filtered off and washed until free from acid. The filtrate was boiled for 20 minutes to remove the hydrogen sulfide, and after cooling was titrated with o.I $N$ sodium hydroxide, using phenolphthalein as an indicator. By subtracting from the acid thus found the total number of equivalents of lead and tin present, the quantity of free acid in the equilibrium mixture was obtained.

\section{Method of Preparing the Equilibrium Mixture.}

Metallic tin and lead were in each experiment placed in $250 \mathrm{cc}$. glassstoppered bottles previously filled with carbon dioxide gas. Solutions of lead perchlorate and tin perchlorate were then introduced into the bottles from a pipet (also previously filled with carbon dioxide). Well fitting stoppers were inserted, covered with sealing wax, and tied down with cloth.

Four bottles were rotated with solutions of each concentration, two starting with pure lead perchlorate solution, and two with pure tin perchlorate solution. In later experiments, after the constant was determined, mixtures of lead and tin perchlorates on each side of, and not far from, the equilibrium concentrations were used.

The bottles were placed in a thermostat at $25.0 \pm 0.1^{\circ}$ (as shown by a standardized thermometer) with their sides along the horizontal axis of the rotating apparatus. In preliminary experiments the bottles were slightly high, but uniformly so. The mean of three closely agreeing analyses of known quantities of lead by electrolyzing it once from nitric acid solution was $0.58 \%$ too high. Therefore, in order to obtain the true weight of $\mathrm{PbO}_{2}$, the weight of the precipitate must be multiplied by 0.9942 , and this was done in computing our results. 
rotated end over end; but in this case the metals welded into very compact bullets, some of which were as much as I $\mathrm{cm}$. in diameter; obviously offering very little surface. But when the bottles were slowly rotated on their sides, the metals merely slipped around the side of the bottle without welding, and maintained a large surface.

The possibility of the formation of solid solutions deserves consideration, in view of the long contact of the two metals with each other. Investigations of the physical alloys of the properties have shown, however, according to Guertler, ${ }^{1}$ that at room temperature the mutual solubilities of the two metals certainly do not exceed a few tenths of one per cent.

\section{The Results of the Equilibrium Measurements.}

The experimental results of the equilibrium measurements are given in Table I. The concentrations are all expressed in milliformula-weights per $1000 \mathrm{~g}$. of soluton. The initial concentrations are only approximate. Those values of the $(\mathrm{Sn}) /(\mathrm{Pb})$ ratio which were obtained in experiments

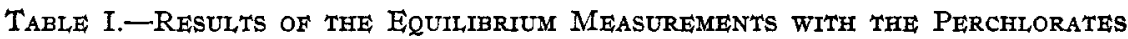
AT $25^{\circ}$.

\begin{tabular}{|c|c|c|c|c|c|c|c|c|}
\hline \multirow{2}{*}{$\begin{array}{l}\text { Sol'n } \\
\text { No. }\end{array}$} & \multirow{2}{*}{$\begin{array}{c}\text { Days } \\
\text { rotated. }\end{array}$} & \multirow{2}{*}{$\begin{array}{l}\text { Initial } \\
\left(\mathbf{S n}_{o}\right) .\end{array}$} & \multirow{2}{*}{$\begin{array}{c}\text { Concen- } \\
\text { trations. } \\
\left(\mathrm{Pb}_{0}\right) .\end{array}$} & \multicolumn{3}{|c|}{ Final concentrations. } & \multirow{2}{*}{$\operatorname{Sum}_{(\mathrm{Sn})+(\mathrm{Pb})}$} & \multirow{2}{*}{$\begin{array}{c}\text { Ratio } \\
(\mathrm{Sn}) /(\mathrm{Pb})\end{array}$} \\
\hline & & & & (Sn). & $\overbrace{(\mathrm{Pb}) .}$ & $\overline{(\mathrm{H})}$. & & \\
\hline I & IO & o & 96 & 71.62 & 24.15 & 530 & $95 \cdot 76$ & $2.968^{*}$ \\
\hline 2 & IO & 94 & o & 70.37 & $23 \cdot 34$ & 512 & 93.71 & 3.015 \\
\hline 3 & I 3 & o & 96 & $71 \cdot 57$ & 23.66 & 532 & 95.23 & $3.025^{*}$ \\
\hline \multirow[t]{2}{*}{4} & I3 & 94 & o & 70.72 & $23 \cdot 48$ & 5 I 3 & 94.20 & 3.012 \\
\hline & & & & & & & Av., & $\begin{array}{r}3.005 \\
\pm 0.020\end{array}$ \\
\hline 5 & 12 & 0 & 60 & 45.67 & 14.83 & 475 & 60.50 & $3.080^{*}$ \\
\hline 6 & I 2 & 50 & 0 & $39.3 \mathrm{I}$ & 12.34 & $47^{8}$ & 51.65 & 3.186 \\
\hline 7 & I2 & 0 & 50 & 36.88 & I 1.86 & 502 & 48.74 & $3.110^{*}$ \\
\hline \multirow[t]{2}{*}{8} & 12 & 50 & o & $4 I \cdot 34$ & 13.17 & 454 & $54.5 \mathrm{I}$ & 3.139 \\
\hline & & & & & & & Av., & $\begin{array}{r}3.124 \\
\pm 0.034\end{array}$ \\
\hline 9 & I6 & $5 I$ & 37 & $69 \cdot 74$ & $23.9 \mathrm{I}$ & 902 & 93.65 & $2.917^{*}$ \\
\hline IO & 16 & 66 & 27 & 69.17 & 23.46 & 865 & 92.63 & $2.948^{*}$ \\
\hline II & I9 & 79 & $3 I$ & 80.83 & 27.20 & $75 I$ & 108.01 & $2.976^{*}$ \\
\hline \multirow[t]{2}{*}{12} & 19 & 86 & 24 & 82 . II & 27.51 & 832 & 109.62 & 2.985 \\
\hline & & & & & & & Av., & $\begin{array}{r}2.956 \\
\pm 0.024\end{array}$ \\
\hline 13 & ro & 38 & I9 & 42.80 & 14.47 & 930 & 57.27 & $2.958^{*}$ \\
\hline 14 & 10 & 46 & 14 & 45.20 & 15.01 & 959 & 60.21 & 3.011 \\
\hline \multirow[t]{2}{*}{15} & 12 & 54 & 14 & 50.80 & I7.II & 853 & $67.9 I$ & 2.969 \\
\hline & & & & & & & Av., & $\begin{array}{r}2.979 \\
\pm 0.021\end{array}$ \\
\hline
\end{tabular}

${ }^{1}$ Guertler's Metallographie, I, 728. 
where the equilibrium was approached from solutions containing an excess of lead are indicated by an asterisk. It will be seen that these ratios are on average only about $\mathrm{I} \%$ lower than those obtained in approaching the equilibrium from the other side.

\section{Value of the Equilibrium Ratio.}

Assuming the perchlorates of lead and tin are equally ionized, the ratio $(\mathrm{Sn}) /(\mathrm{Pb})$ is equal to the ion-concentration ratio $\left(\mathrm{Sn}^{++}\right) /\left(\mathrm{Pb}^{++}\right)$, which according to the mass-action law should have a constant value. It will be seen that this equilibrium ratio does in fact have not far from the same average value in the first, third, and fourth group of experiments, but that it has a considerably higher value in the second group. In this group the acid concentration and the total metal-ion concentration were both small; and it seems not improbable that the higher value of the ratio arises from hydrolysis of the stannous perchlorate. Leaving out this group of experiments and taking the average of the three others, we get for the equilibrium ratio $\left(\mathrm{Sn}^{++}\right) /\left(\mathrm{Pb}^{++}\right)$the value $2.98 \pm 0.02$, which we shall adopt in our computations of the electrode potentials.

\section{Comparison of the Equilibrium Ratios Obtained with the Per- chlorates and the Chlorides.}

Sackur, in his investigation of the equilibrium of the reaction Sn (solid) $+\mathrm{PbCl}_{2}=\mathrm{Pb}$ (solid) $+\mathrm{SnCl}_{2}$, obtained average values of the ratio $(\mathrm{Sn}) /(\mathrm{Pb})$ which are summarized in Table II, the concentrations being all expressed in milliformula-weights per liter.

Table II,-Results of SackuR's Equilibrium Measurements with the Chlorides AT $25^{\circ}$.

\begin{tabular}{lcccc}
\multicolumn{3}{c}{ Final concentrations. } & $\begin{array}{c}\text { Sum } \\
(\mathrm{Sn})+(\mathrm{Pb}) .\end{array}$ & $\begin{array}{c}\text { Ratio } \\
(\mathrm{Sn}) /(\mathrm{Pb}) .\end{array}$ \\
\hline $\begin{array}{c}(\mathrm{Su}) . \\
14.23\end{array}$ & 4.60 & 1000 & 18.83 & 3.09 \\
18.75 & 5.62 & 500 & 24.37 & 3.34 \\
21.10 & 6.32 & 400 & 27.42 & 3.34 \\
24.45 & 7.17 & 300 & 31.62 & 3.41 \\
32.30 & 9.37 & 200 & 41.67 & 3.45
\end{tabular}

It will be seen that the ratio $(\mathrm{Sn}) /(\mathrm{Pb})$ has (except in the most concentrated acid solution) a considerably higher value than that (2.98) found in the experiments with the perchlorates, showing that a smaller proportion of the tin or larger proportion of lead is present in the form of the simple ions $\left(\mathrm{Sn}^{++}\right.$or $\mathrm{Pb}^{++}$) in the chloride than in the perchlorate solution. The more striking fact, however, is not that there is a difference between the two types of salt, but that this difference is so small, indicating that there is no large formation of a complex acid, such as $\mathrm{H}+\mathrm{SnCl}_{3}{ }^{-}$, in the chloride solution up to the concentrations involved. 


\section{Difference between the Specific Electrode Potentials of Tin and Lead.}

The difference $\left(\overline{\mathrm{E}}_{\mathrm{Sn}}-\overline{\mathrm{E}}_{\mathrm{Pb}}\right)$ between the specific or normal electrode potentials of tin and lead can be readily calculated from the fact that in the equilibrium mixture the two actual electrode potentials $\mathbf{E}_{\mathbf{S n}}$ and $\vec{E}_{P b}$ must be equal, whence follows:

or

$$
\overline{\mathrm{E}}_{\mathrm{Sn}}-(R T / 2 \mathrm{~F}) \log _{e}\left(\mathrm{Sn}^{++}\right)=\mathrm{E}_{\mathrm{Pb}}-(R T / 2 \mathrm{~F}) \log _{e}\left(\mathrm{~Pb}^{++}\right)
$$

$$
\overline{\mathrm{E}}_{\mathrm{Sn}}-\overline{\mathrm{E}}_{\mathrm{Pb}}=\frac{R T}{2 \mathrm{~F}} \log _{e} \frac{\left(\mathrm{Sn}^{++}\right)}{\left(\mathrm{Pb}^{++}\right)}
$$

Substituting in this expression the value $2.98 \neq 0.02$ of the equilibrium ratio $(\mathrm{Sn}) /(\mathrm{Pb})$ found in the perchlorate experiments, we find for the difference in the electrode potentials at $25^{\circ}$

$$
\overline{\mathbf{E}}_{\mathrm{Sn}}-\overline{\mathbf{E}}_{\mathrm{Pb}}=+0.0140 \pm 0.000 \text { volt. }^{1}
$$

Even if the ionizations of the tin and lead perchlorates really differed by as much as $8 \%$, instead of being equal as assumed, this result would be in error by only o.oor volt.

\section{I0. The Specific Electrode Potentials of Lead and Tin.}

The specific electrode potential of lead can be derived most accurately in the following manner:

Brönsted ${ }^{2}$ measured at a series of temperatures the electromotive forces of cells of the following type:

$$
\mathrm{Pb}(0.72 \%) \text { in } \mathrm{Hg}, \mathrm{PbCl}_{2} \text { at conc. c, } \mathrm{AgCl} \text { (solid) }+\mathrm{Ag}
$$

The data for these cells at $25^{\circ}$ are given in the following table. The measured electromotive forces are represented by E. The concentrations $c$ are expressed in mols per $1000 \mathrm{~g}$. water. The ionizations $\gamma$ are graphically interpolated from the values derived by Hunt ${ }^{3}$ from his conductance measurements. The electromotive forces $\overline{\mathrm{E}}$ are computed for the case that the lead ion and chloride ion are each $\mathrm{I}$ molal by the equation

$$
\begin{array}{cccc}
\multicolumn{4}{c}{\overline{\mathrm{E}}=\mathrm{E}+\frac{R T}{\mathrm{~F}} \log 2(c \gamma)^{\mathrm{i} / 2} .} \\
\text { E. } & c . & \gamma . & \text { E. } \\
0.4766 & 0.0389 & 0.562 & 0.3470 \\
0.4871 & 0.0265 & 0.614 & 0.3463 \\
0.5146 & 0.00984 & 0.734 & 0.3425 \\
& & & \text { Mean, } \begin{array}{c}
0.3453 \\
\pm 0.0018
\end{array}
\end{array}
$$

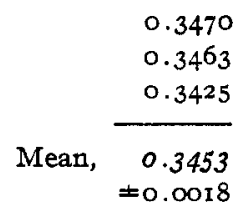

1 Here and throughout this article electrode potentials are given a positive sign when positive electricity tends to flow from the electrode to the solution, a convention opposite to that commonly employed by foreign electrochemists.

${ }^{2} Z$. phys. Chem., 56, 665-667 (1906).

8 ThIS JOURNAL; 33, 802 (I9II). 
Brönsted $^{1}$ also measured the electromotive force of the cell $\mathrm{Pb}$ (solid), $\mathrm{PbCl}_{2}$ (0.0984 molal), $\mathrm{Pb}(0.72 \%$ in $\mathrm{Hg}$ ), and found it to be +0.0109 volt at $25^{\circ}$. Adding this value to the mean value $(0.3453)$ just obtained we get $+0.3562 \neq 0.0018$ as the electromotive force of the cell $\mathrm{Pb}$ (solid), $\mathrm{Pb}^{++}\left({ }_{\mathrm{I}} M.\right) / / \mathrm{Cl}^{-}(\mathrm{I} M$. $), \mathrm{AgCl}$ (solid) $+\mathrm{Ag}$.

Accurate measurements, not yet published, of the electromotive force of the cell $\mathrm{H}_{2}(\mathrm{I}$ atm.), $\mathrm{HCl}(0.03326 \mathrm{M}$.), $\mathrm{AgCl}$ (solid) $+\mathrm{Ag}$, have been made in this laboratory by J. H. Ellis. He found the electromotive force of this cell to be 0.4055 volt at $25^{\circ}$. Now, according to the computations made by Ellis ${ }^{2}$ upon the basis of Jahn's electromotive force data, the activity coefficient (or effective ionization) of hydrochloric acid at this concentration is 0.886 . From these values the electromotive force of the cell, $\mathrm{Ag}+\mathrm{AgCl}$ (solid), $\left.\left.\mathrm{Cl}^{-}{ }_{\mathrm{I}} M.\right) \| \mathrm{H}+{ }_{\mathrm{I}} M.\right), \mathrm{H}_{2}$ ( $\mathrm{I}$ atm.) is computed by the usual logarithmic concentration formula to be -0.2246 volt. ${ }^{3}$ Additg this electromotive force to the value 0.3562 volt found above we get for the specific electrode potential of lead at $25^{\circ}$ referred to the molal hydrogen electrode the value

$$
\overline{\mathrm{E}}_{\mathrm{Pb}}=+0.132 \neq 0.002 \text { volt. }
$$

Combining this value with the difference between the specific electrode potentials of tin and lead derived in the preceding section of this article we get for the specific electrode potential of tin at $25^{\circ}$ the value

$$
\overrightarrow{\mathrm{E}}_{\mathrm{Sn}}=+0.146 \pm 0.002 \text { volt. }
$$

Although the experimental accuracy of these potentials is indicated to be \pm 0.002 volt, they may be subject to a larger error than this, because of the fact that the lead-ion concentration in lead chloride was calculated in the usual way from the equivalent conductance ratio. When the electrode potential of lead becomes better known, that of tin can be recomputed with the aid of our equilibrium measurements, and thus determined more accurately.

The values of the specific potentials adopted by Auerbach on the basis of previous electromotive-force measturements in his recently published monograph ${ }^{4}$ are 0.12 for lead and 0.10 for tin, thus placing the two metals in an order in the electromotive series opposite to that shown by our equilibrium measurements with the perchlorates, as well as by those of Sackur with the chlorides. Auerbach's conclusion as to the position of tin seems to have been based only on the results of Sackur ${ }^{5}$ on thee lectromo-

1 Loc. cit., p. 668.

2 Ellis, This JourNaI, 38, 756-759 (I9I6).

This value is evidently the specific electrode-potential of the half cell $\mathrm{Ag}+\mathrm{AgCl}$ (solid), $\mathrm{Cl}^{-}$.

" "Messungen elektromotorisher Kräfte galvanischer Ketten," Erstes Erganzungsheft, p. 58 (19I5).

${ }^{5}$ Arb. kais. Gesundh., 20, 542 (I904); Z. Electrochem., 10, 525 (1904). 
tive force of cells of the type $\mathrm{Sn}, \mathrm{Sn}\left(\mathrm{NO}_{3}\right)_{2}$ (0.007 to o. ro $\left.N\right), \mathrm{KNO}_{3}(0.5 N)$, $\mathrm{KCl}(\mathrm{I} N), \mathrm{Hg}_{2} \mathrm{Cl}_{2}+\mathrm{Hg}$, and of corresponding cells in which the tin was replaced by lead and the stannous nitrate by lead nitrate. In view of the instability of stannous nitrate and the liquid potentials involved, these results seem far less conclusive than the equilibrium measurements with the perchlorates.

\title{
II. Summary.
}

In this article have been described determinations of the equilibrium between metallic tin and lead and lead perchlorate and stannous perchlorate in dilute perchloric acid solution at $25^{\circ}$. These determinations have given the value 2.98 for the equilibrium ratio of the tin and lead concentrations in this solution, while Sackur found for this ratio the value 3.34 to 3.45 in dilute solutions of the two chlorides.

Assuming that the value 2.98 represents also the ratio $\left(\mathrm{Sn}^{++}\right) /\left(\mathrm{Pb}^{++}\right)$ of the concentrations of the tin ion and lead ion in the perchlorate solution, the specific electrode potential of tin is computed to be 0.0140 volt larger than that of lead.

From electromotive force data existing in the literature the specific electrode potential of lead referred to the molal hydrogen electrode has been recomputed and found to be +0.132 volt. That of tin then becomes +0.146 volt. These values are probably accurate within \pm 0.002 volt, so far as they are influenced only by experimental errors.

Cambridge, Mass.

[Contriaution from the Chemistry Department of the University of Ilimois.]

\section{HETEROGENEOUS EQUILIBRIA BETWEEN AQUEOUS AND METALLIC SOLUTIONS: THE INTERACTION OF MIXED SALT SOLUTIONS AND LIQUID AMALGAMS.}

\author{
[FOURTH PAPER.]
}

\section{A STUDY OF THE IONIZATION RELATIONS OF SODIUM AND STRONTIUM CHLORIDES IN MLXTURES.}

By G. MCP. SMIth aNd S. A. Braing. 1

Received May 29, 1917.

Contents.-A. Introduction: I. Purpose of the Investigation. 2. Principles Relating to the Ionization of Salts in Mixtures. B. Theoretical: I. The Aqueous Solution. 2. The Metallic Solution. C. Materials, Apparatus and Method of Experimentation. D. Experimental Data: $x$. Effect of Varying the Concentration of the Liquid Amalgam. 2. Effect of Increasing the Total Salt Concentration at a Fixed (Equivalent) Salt-concentration Ratio, and at Various Fixed Amalgam Concentrations. 3. Effect of Varying the Concentration Ratio of the Salts at a Fixed Total Concentration. 4. Effect of Changing the Temperature: Heat of Reaction. 5. Calculation of the Ion Fractions in Cases 2 and 3. 6. Calculation of the Change

1 Thesis submitted to the Graduate School of the University of Illinois by S. A. Braley in partial fulfilment of the requirements for the degrees of Doctor of Philosophy. 